\title{
Psychometrics of the preschooler physical activity parenting practices instrument among a Latino sample
}

Teresia M O'Connor ${ }^{1,2^{*}}$, Ester Cerin ${ }^{3,4}$, Sheryl O Hughes ${ }^{1}$, Jessica Robles ${ }^{1}$, Deborah I Thompson ${ }^{1}$, Jason A Mendoza ${ }^{1,6}$, Tom Baranowski ${ }^{1}$ and Rebecca E Lee ${ }^{5}$

\begin{abstract}
Background: Latino preschoolers (3-5 year old children) have among the highest rates of obesity. Low levels of physical activity (PA) are a risk factor for obesity. Characterizing what Latino parents do to encourage or discourage their preschooler to be physically active can help inform interventions to increase their PA. The objective was therefore to develop and assess the psychometrics of a new instrument: the Preschooler Physical Activity Parenting Practices (PPAPP) among a Latino sample, to assess parenting practices used to encourage or discourage PA among preschool-aged children.
\end{abstract}

Methods: Cross-sectional study of 240 Latino parents who reported the frequency of using PA parenting practices. $95 \%$ of respondents were mothers; $42 \%$ had more than a high school education. Child mean age was $4.5( \pm 0.9)$ years (52\% male). Test-retest reliability was assessed in 20\%, 2 weeks later. We assessed the fit of a priori models using Confirmatory factor analyses (CFA). In a separate sub-sample (35\%), preschool-aged children wore accelerometers to assess associations with their PA and PPAPP subscales.

Results: The a-priori models showed poor fit to the data. A modified factor structure for encouraging PPAPP had one multiple-item scale: engagement (15 items), and two single-items (have outdoor toys; not enroll in sport-reverse coded). The final factor structure for discouraging PPAPP had 4 subscales: promote inactive transport ( 3 items), promote screen time ( 3 items), psychological control ( 4 items) and restricting for safety ( 4 items). Test-retest reliability (ICC) for the two scales ranged from 0.56-0.85. Cronbach's alphas ranged from 0.5-0.9. Several sub-factors correlated in the expected direction with children's objectively measured PA.

Conclusion: The final models for encouraging and discouraging PPAPP had moderate to good fit, with moderate to excellent test-retest reliabilities. The PPAPP should be further evaluated to better assess its associations with children's PA and offers a new tool for measuring PPAPP among Latino families with preschool-aged children.

Keywords: Physical activity, Parenting practices, Latino, Hispanic, Preschool child, Confirmatory factor analysis

\section{Background}

Overweight and obesity among children have increased dramatically over the past decades. Latino children appear to be particularly susceptible to obesity even as preschoolers [1], and obesity-related metabolic and endocrine diseases as they get older [2]. Regular engagement in

\footnotetext{
*Correspondence: teresiao@bcm.edu

'USDA/ARS Children's Nutrition Research Center, Department of Pediatrics,

Baylor College of Medicine, 1100 Bates St, Houston, TX 77030, USA

${ }^{2}$ Academic General Pediatrics, Department of Pediatrics,

Baylor College of Medicine, Houston, TX, USA

Full list of author information is available at the end of the article
}

physical activity (PA) appears to reduce the risk of obesity among preschool children [3,4] particularly male preschoolers [5]. Moreover, PA may track over time in children [6], suggesting that establishing higher levels of PA in young children might be beneficial. PA for children has been defined as: "bodily movement produced by skeletal muscles that results in energy expenditure, including active play, active transportation, household chores, sports participation, and exercise" (page 142) [7] adapted from Caspersen's definition [8]. Preschool children should get at least 60 minutes of structured PA (such as organized
C Biomed Central

(c) 2014 O'Connor et al.; licensee BioMed Central Ltd. This is an open access article distributed under the terms of the Creative Commons Attribution License (http://creativecommons.org/licenses/by/2.0), which permits unrestricted use, distribution, and reproduction in any medium, provided the original work is properly cited. 
active play) and at least 60 minutes of unstructured PA (such as free play) daily [9].

According to Social Ecologic [10] and Social Cognitive Theories [11], PA is multi-factorial and influenced by individual, social, and physical environmental variables. For children, parents are an important social influence, influencing their PA directly, but also indirectly through children's attraction to PA and perceived competence for PA [12]. Decades of research on parental influences on children's behaviors support that parents are an important determinant of children's socialization and behaviors, both through their parenting style and their parenting practices [13]. Darling and Steinberg defined parenting styles by the values and goals parents have in raising their child, the attitudes that the parents have regarding the parent-child relationship, and the parenting practices they use to attain their desired outcomes [13]. The parenting style employed is believed to establish the emotional climate between the parent and the child. Parenting practices, on the other hand, are goal oriented parenting behaviors that are specific to a context and intended to influence their child's behavior in that context [13] (e.g. rules around homework or promoting PA). While physical activity parenting practices have been identified and linked to children's PA among older children [14-16], few instruments have been developed to assess parenting practices in the context of PA for preschoolers.

A recent systematic review of PA parenting questionnaires [16] identified 11 available PA parenting instruments. Only one was intended for preschool-aged children [17]; and another [18], originally intended for school aged children, was used among preschoolers [16]. The review acknowledged that several measures lacked theoretical foundation, qualitative formative research, and/or appropriate validation studies, including psychometric analysis of the scales. They called for the development of comprehensive multi-dimensional PA parenting measures with appropriate validation prior to use. It is possible that the use of non-validated PA parenting scales is the reason for sometimes failing to identify associations of PA parenting practices with preschoolers' PA in multivariate models in previous studies [19]. Other reviews have identified the lack of studies that investigated potential negative parent social support for PA that may inhibit PA or promote inactivity, and encourage investigation into this construct [20].

Among older children, parents can be an important influence on children's PA, through active role modeling, direct involvement, encouragement, and providing transportation [21]. It is unclear if these same parenting practices are used by parents of preschool aged children or if they influence preschooler's PA. Since cultural variables influence parenting [22] and children's PA behaviors [23], a PA parenting practice instrument developed for use with Latino parents should be informed by qualitative studies with Latino parents. The aim of this study was therefore to a) develop a new multi-dimensional, self-report measure of Preschoolers' PA Parenting Practices (PPAPP), and b) examine the psychometric properties (reliability, construct/factor validity and criterion validity) of the newly-developed PPAPP among a Latino sample.

\section{Methods \\ Development of the PPAPP instrument}

Darling and Steinberg [13] identified that parenting practices are not the same for all contexts and need to be operationalized for each specific context (e.g. PA parenting practices). The PPAPP instrument was therefore developed based on a qualitative formative study with Latino parents of preschool children [24], and the structure informed by current parenting paradigms [25-27] and research on parental influences on child PA [28-32].

The qualitative formative work used Nominal Group Technique (NGT) [33,34], a structured multi-step group procedure to prompt and prioritize responses from a group of people in reaction to a question or problem. Ten NGT groups $(\mathrm{n}=74)$ were conducted with Latino parents who were mostly mothers. Five groups were asked to identify what Latino parents do to encourage their preschool aged child to be physically active, and 5 were asked to identify what Latino parents do that may discourage their preschool aged child to be physically active. The prioritizations of responses from the five groups who addressed the same question were aggregated into rank order lists across the groups of the PA parenting practices that encourage or discourage Latino preschool children to be physically active and have been published elsewhere [24]. We used the two prioritized lists to develop 38 items for PA parenting practices; based on parent responses in the NGT sessions the items were identified as encouraging child PA (21 items) or discouraging child PA (17 items).

The items in each list were then grouped into parenting practice factors for parenting practices that Encourage PA and those that Discourage PA separately, based on constructs that have been identified for physical activity or other contexts of parenting [25-32]. The primary theoretical framework for PA parenting employed to organize the items into factors was based on a framework outlined by a working group of physical activity and parenting experts [32]. This working group [32] recommended that PA parenting practices be aligned along three previously defined dimensions of parenting: responsiveness, structure and control [25-27,35]. Parental responsiveness of PA was defined as the practices parents use to show warmth, autonomy support and reasoned communication to foster child PA individuality 
and self-assertion in PA [32]. Parental structure for PA was defined as how parents organize the physical environment to foster child competence in PA [32]. It was hypothesized that parenting practice items that encouraged child PA would measure these two factors: responsiveness and structure [32] (Figure 1). In addition, the working group suggested there may be parenting practices that negatively impact children's PA [32], such as a control or demandingness dimension for PA. This PA dimension was defined as directive, restrictive and punitive parenting practices that force the child to be physically active. Based on this, items describing parenting practices that discouraged children from being physically active were hypothesized to measure three factors: psychological control, restriction due to safety concerns, and promotion of inactivity (Figure 2). Psychological control was defined as strategies to mold child behaviors through manipulation to satisfy the parents' needs [25] and restriction due to safety concerns was defined as restricting activity due to concern for the child's safety [28]. The third factor - promote inactivity - was not based on parental control, and was defined as parenting behaviors that promoted sedentary behaviors in children. This factor was added based on previous investigations by other PA parenting researchers $[17,31]$.

Separate a priori reflective models [36] for parenting practices encouraging PA and discouraging PA were constructed for several reasons. First, there is some preliminary evidence that parenting practices that discourage PA may have a greater effect on preschooler's PA than those that encourage PA, as children of this age tend to be active [37]. Second, effective and ineffective fruit and vegetable parenting practices exist as separate constructs in separate models [38,39], lending support to possible separate constructs in other parenting practice contexts. In this regard, a model of parenting practices to encourage and discourage PA based on data from this study showed that latent factors representing the two types of parenting practices were essentially independent. Third, specific practices discouraging PA may be negatively related to practices encouraging PA. Thus, a combined measurement model of parenting practices encouraging and discouraging PA would likely be overly complex with many items loading on multiple latent factors. In fact, when a combined model was tested in this study, six items loaded (in the opposite direction) onto latent factors representing both practices discouraging and encouraging PA.

The instructions for the instrument were to choose "the best answer for how often you do each of the following with your 3-5 year old child". A 5-point Likert response scale was used (never, rarely, sometimes, often, and always). The questionnaire was first developed in English, then translated into Spanish by a staff member fluent in Spanish and English, and independently backtranslated into English by a second bilingual staff to ensure content validity between the English and Spanish versions. Differences in the original and back-translated versions were reviewed and consensus was reached for conceptual and cultural rather than linguistic equivalence. Cognitive interviews $[40,41]$ were conducted with 10 parents while completing the PPAPP instrument and
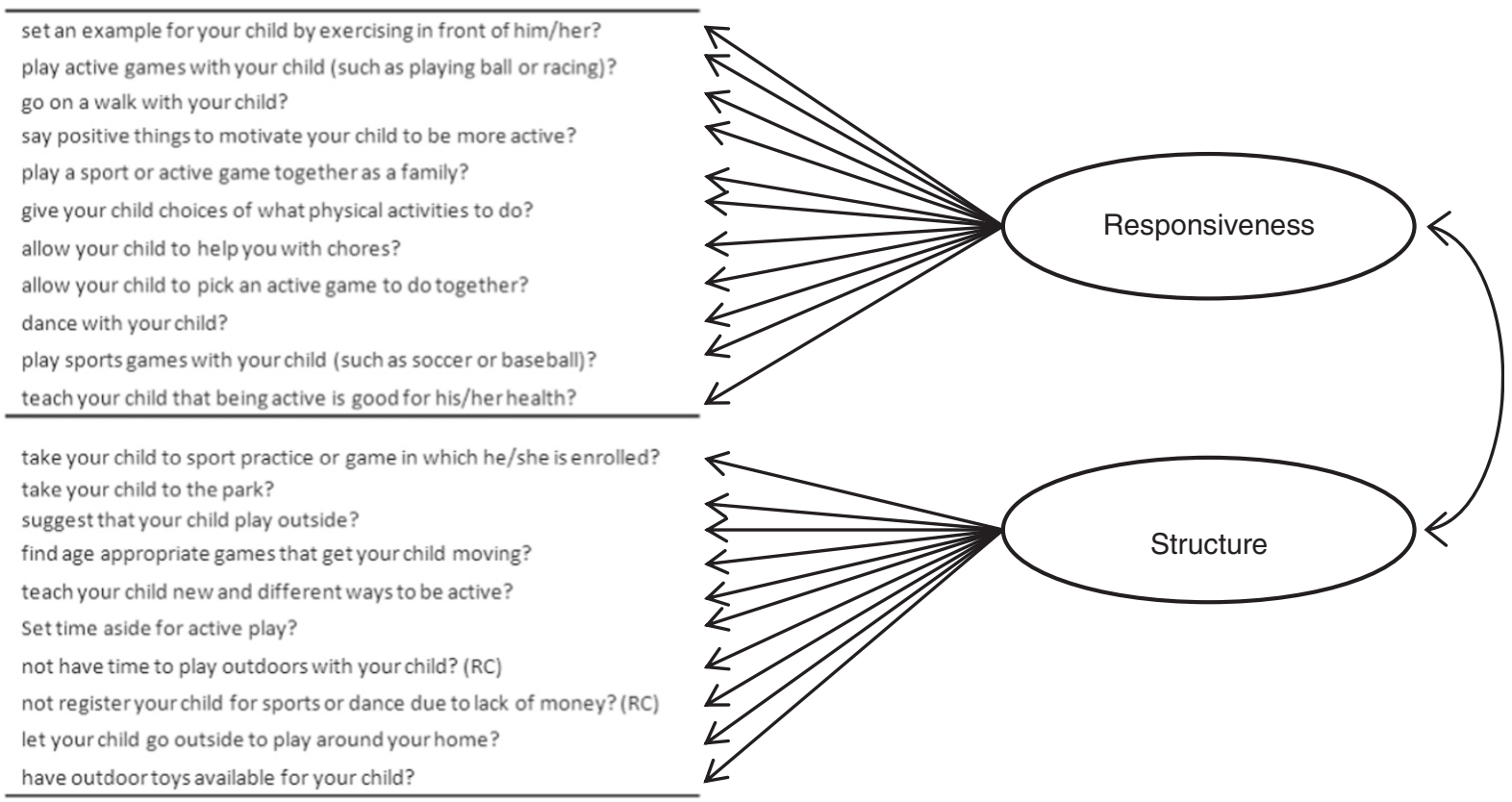

Figure 1 Proposed model for parenting practices that encourage Latino preschooler's physical activity. 


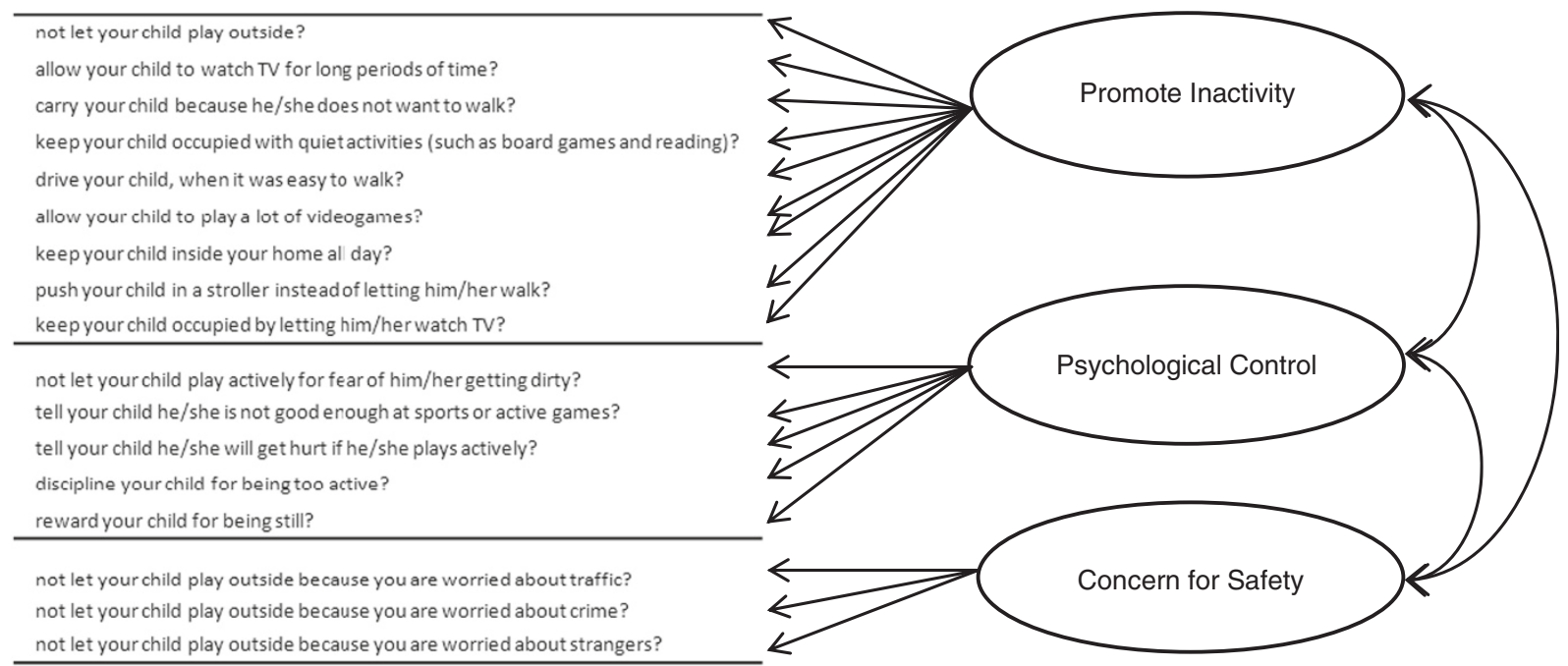

Figure 2 Proposed model for parenting practices that discourage Latino preschooler's physical activity.

other instruments in the study. Five were conducted in Spanish and 5 in English to assess parents' understanding of the instructions, items and response options. In general, the parents correctly interpreted the PPAPP items and response options in both languages. The cognitive interviews resulted in minor rewording of four of the 38 items to enhance clarity.

\section{Validation study}

\section{Sample and recruitment}

A cross-sectional study with Latino parents of preschool aged children residing in Harris County, Texas (where Houston is located) was conducted. Since neighborhood crime and traffic safety may impact children's PA [42], this study aimed to recruit Latino parents from neighborhoods cross-stratified by these neighborhood characteristics. Crime data at the census block group level for Harris County were obtained from Tetrad Inc (Vancouver, British Columbia; http://www.tetrad.com) who modeled a crime index based on FBI Uniform Crime Report data from 1998- 2007, including personal (murder, rape, robbery, and assault) and property (burglary, larceny, and motor-vehicle thefts) crimes. Traffic-related injury data at the census block group level from 2004-2008 were obtained from the Houston-Galveston Area Council and included de-identified counts of motor vehicle, pedestrian, and cyclist accidents resulting in injuries or deaths. In addition, the motor vehicle miles traveled for each block group were estimated by the vehicle count per block group divided by the mean distance from center of block group to the border of the block group based on 2000 US census maps [43]. A principle components analysis of the traffic data revealed three factors: (1) motor vehicle injury and fatalities, (2) vehicle miles traveled and pedestrian fatalities, and (3) cyclist fatalities. A traffic safety index was calculated as the sum of the three traffic factor scores for each census block group. Based on median splits of the crime and traffic safety indices, each block group in Harris County was classified as high crime/high traffic; high crime/low traffic; low crime/high traffic; or low crime/low traffic. Recruitment attempted to get equal enrollment of participants from all four types of block groups (about 60 participants from each) and by the gender of the child.

Parents were recruited through various community organizations, events, and fliers posted in various locations; as well as the Children's Nutrition Research Center (CNRC) website and bulletin boards, Baylor College of Medicine (BCM) website, CNRC newsletter, and phone calls to CNRC volunteer list members. Enrolled participants were asked to distribute fliers to Latino friends, relatives or neighbors with preschool aged children who may also be interested in the study. The most common ways enrolled participants reported learning about the study were fliers at clinics (36.3\%), referred by friend or relative (29.2\%), fliers in the community (13.3\%), and contacted as part of the CNRC database $(10.8 \%)$. Parents were enrolled if they met study criteria and provided written informed consent.

After informed written consent was obtained, parents were asked to complete a demographic questionnaire and self-report instruments including the new PPAPP survey. Two hundred forty one self-identified Latino or Hispanic parents completed the study, which included only one parent per household. One family withdrew during the study and their data were removed, leaving a sample of 240 for the analyses. The majority (95\%) were mothers, with $3 \%$ fathers and $1 \%$ other female relative 
(Table 1$)$. The average parent age was 32.3 years $( \pm 6.1)$, and less than half (45\%) of the parents were born in the United States. Thirty percent had less than a high school education, $28 \%$ had completed high school or the equivalent, and $42 \%$ had some education beyond high school. Thirty percent reported a family income of less than $\$ 20,000,48 \%$ from $\$ 20,000$ to $\$ 49,000$; and $18 \%$ more than $\$ 50,000$. Over half of the sample (mostly mothers) reported not being employed currently. The average age of their preschool aged child was $4.5( \pm 0.9)$

Table 1 Parent and child descriptive characteristics

\begin{tabular}{|c|c|c|c|}
\hline Variables & $\begin{array}{l}\text { Whole sample } \\
(n=240)\end{array}$ & $\begin{array}{l}\text { Reliability sub-sample } \\
(n=48)\end{array}$ & $\begin{array}{l}\text { Accelerometer sub-sample } \\
(n=84)\end{array}$ \\
\hline \multicolumn{4}{|l|}{ Parent characteristics } \\
\hline \multicolumn{4}{|l|}{ Relationship to child participant, n (\%) } \\
\hline Mother & $229(95 \%)$ & $44(92 \%)$ & $81(96 \%)$ \\
\hline Other female relative & $3(1 \%)$ & $1(2 \%)$ & $3(4 \%)$ \\
\hline Father & $8(3 \%)$ & $3(6 \%)$ & 0 \\
\hline Age, mean (SD) & $32.3(6.1)$ & $31.5(5.6)$ & $32.7(6.7)$ \\
\hline Born in the US, $\mathrm{n}(\%)$ & $108(45 \%)$ & $22(46 \%)$ & $36(43 \%)$ \\
\hline \multicolumn{4}{|l|}{ Education, n (\%) } \\
\hline$<$ High School & $72(30 \%)$ & $18(38 \%)$ & $24(29 \%)$ \\
\hline High School/GED & $67(28 \%)$ & 15 (31\%) & $22(26 \%)$ \\
\hline > High School & $101(42 \%)$ & $15(31 \%)$ & $37(44 \%)$ \\
\hline Not answered & $1(<1 \%)$ & NA & $1(1 \%)$ \\
\hline \multicolumn{4}{|l|}{ Current employment status, n (\%) } \\
\hline Not employed & $129(54 \%)$ & $31(65 \%)$ & $50(60 \%)$ \\
\hline Part-time & $42(17.5 \%)$ & $3(6 \%)$ & $15(18 \%)$ \\
\hline Full-time & $59(25 \%)$ & $14(29 \%)$ & $16(19 \%)$ \\
\hline$>40 \mathrm{hr} / \mathrm{wk}$ & $9(4 \%)$ & $\mathrm{n} / \mathrm{a}$ & $2(2 \%)$ \\
\hline Not answered & $1(<1 \%)$ & $\mathrm{n} / \mathrm{a}$ & $1(1 \%)$ \\
\hline \multicolumn{4}{|l|}{ Total household income, n (\%) } \\
\hline$\leq \$ 19 \mathrm{k}$ & $72(30 \%)$ & $14(29 \%)$ & $29(35 \%)$ \\
\hline$\$ 20 k-\$ 49 K$ & $116(48 \%)$ & $22(46 \%)$ & 37 (44\%) \\
\hline$\geq \$ 50 k$ & $42(18 \%)$ & $10(21 \%)$ & $13(15 \%)$ \\
\hline Unknown/No answer & $10(4 \%)$ & $2(4 \%)$ & $5(6 \%)$ \\
\hline \multicolumn{4}{|l|}{ Primary language spoken in household, n (\%) } \\
\hline English & $46(19 \%)$ & $11(23 \%)$ & $11(13 \%)$ \\
\hline Spanish & $103(43 \%)$ & $22(46 \%)$ & $39(46 \%)$ \\
\hline Both & $91(38 \%)$ & 15 (31\%) & $34(41 \%)$ \\
\hline \multicolumn{4}{|l|}{ Child characteristics } \\
\hline Age, mean (SD) & $4.5(0.9)$ & $4.4(0.8)$ & $4.4(0.8)$ \\
\hline \multicolumn{4}{|l|}{ Gender, n (\%) } \\
\hline Female & $115(48 \%)$ & $20(42 \%)$ & 37 (44\%) \\
\hline Male & $125(52 \%)$ & $28(58 \%)$ & $47(56 \%)$ \\
\hline Born in the US, $\mathrm{n}(\%)$ & 237 (99\%) & $48(100 \%)$ & $83(99 \%)$ \\
\hline \multicolumn{4}{|l|}{ Child physical activity (PA) } \\
\hline Sedentary, min/day (SD) & & & $369.1(70.9)$ \\
\hline Light PA, min/day (SD) & & & $247.0(36.6)$ \\
\hline Moderate-to-vigorous PA, min/day (SD) & & & $83.4(38.3)$ \\
\hline Counts/min, mean (SD) & & & $611.8(230.5)$ \\
\hline
\end{tabular}


years old and $52 \%$ reported having a preschool aged boy. The majority of the children were born in the US (99\%); and $43 \%$ reported speaking mostly Spanish at home, 19\% mostly English and 38\% both English and Spanish. Just over half (53.3\%) completed the questionnaires in Spanish and the remainder in English (Table 1).

Similar to other studies [44-46], a sub-sample $(n=48$, $20 \%$ of the total sample) was asked to complete the questionnaire a second time (two weeks later) to estimate the test-retest reliability of the instrument. A second sub-sample of parents $(n=85,35 \%)$, with some overlap with the first, provided additional consent to have their 3-5 year old child wear data collection monitors, including an accelerometer for a week. All participants were offered the opportunity to participate in the test-retest and objective PA assessment components of the study. Participants who expressed interest were consecutively enrolled in the test-retest subsample until the pre-set quota (20\%) was met. The goal was to also stratify children by neighborhood type and gender to qualify to participate in the objective PA assessment study subcomponent and consecutively enrolled until the pre-set quota (35\%) was met. The two sub-samples had similar demographic characteristics (Table 1). The study was approved by the Baylor College of Medicine Institutional Review Board. Participants received \$20 in compensation for completing the questionnaires, and $\$ 20$ if they completed the same questionnaires two weeks later. Participants whose preschool-aged child wore the monitors for one week received an additional \$30 if the parent completed a monitor wear log during that week, and the data met quality criteria described below.

\section{Child PA}

Eighty-five children wore Actigraph GT3X accelerometers recording at 15 second epochs on their right hip [47] on an elastic fitted belt for 7 days. One family withdrew during the study, and data were removed from further analyses, leaving a sample of 84. Parents were instructed to remove the monitors at night when the child was sleeping and when the child was bathing or swimming to avoid getting the monitors wet. Parents completed a monitor wear log for their child and the non-wear time reported by the parent was removed, along with consecutive " 0 " counts for $\geq 30$ minutes. The accelerometer data were considered complete if after processing, there were $\geq 480$ minutes of activity data/day for at least four days, including one or more weekend days. Allowing for re-wears, 82 (96\%) children had valid data. Data were processed using Pate's cut points for preschool children [48] with 0-37 counts/15 seconds defined as sedentary, 38-419 counts/15 seconds as light PA (LPA), 420-841 counts/15 seconds as moderate PA (MPA), and $\geq 842$ counts/15 seconds as vigorous PA
(VPA) $[48,49]$. In addition, counts per minute (CPM) were used to assess overall daily activity. These cutpoints have been validated with preschool children's oxygen consumption during activities [48].

\section{Data analyses}

Confirmatory factor analyses (CFAs) based on the Maximum Likelihood Estimation method were used to assess the fit of the data to a priori models. Jöreskog and Sörbom's iterative model-generating approach was used to re-specify the models and was guided by an inspection of standardized factor loadings, standardized residual covariances, univariate Langrage multiplier tests, Wald tests, multivariate outliers, and theoretical considerations [50]. Global model fit was tested using the comparative fit index (CFI), the root mean square error of approximation (RMSEA), and the standardized root mean squared residual (SRMR) [51,52]. According to $\mathrm{Hu}$ and Bentler [51], values supportive of good model fit are $\geq 0.95$ for CFI, $\leq 0.06$ for RMSEA, and $\leq 0.08$ for SRMR. Given that the CFI is sensitive to the magnitude of correlations between variables [52], we treated CFI values $\geq 0.90$ as indicative of acceptable levels of model fit if the other two fit indices met $\mathrm{Hu}$ and Bentler's stricter criteria. We also reported the Satorra-Bentler scaled $\chi^{2}$ test (robust to violation to the normality of distribution assumption) [53]. The following parameters were used to examine local fit of the models: standardized factor loadings, standardized residual covariances, univariate Langrage multiplier tests and Wald tests. Eqs 6.2 (Multivariate Software Inc., Encino, CA, 2010) was used to conduct CFAs.

Intra-class correlation coefficients (ICCs) were computed to establish the test-retest reliability of the PPAPP subscales and single items derived from the final measurement models. ICCs were computed using absoluteagreement in two-way random models [54]. ICC values up to .20 denote poor reliability; .21-.40 fair reliability; .41-.60 moderate reliability; .61-.80 substantial level of reliability; and > .80 excellent reliability [55]. Cronbach's alpha coefficients and mean inter-item correlation were computed to establish the internal consistency of the subscales in the total sample. Cronbach's alphas were also calculated separately for instruments completed in English and Spanish. Mean inter-item correlations were also calculated as a more straightforward assessment of internal consistency that is not item number sensitive, with values ranging from $.15-.50$ considered indicative of an adequate level of internal consistency [56].

Associations of PA parenting practice subscales/items with child PA were assessed using hierarchical regression analyses whereby accelerometer wear-time, child's gender and child's age (potential confounders) were entered in the regression models in a first step, and a specific 
Table 2 Fit indices of a priori of measurement models of parenting practices that encouraged or discouraged physical activity (PA) among Latino preschool children

\begin{tabular}{llll}
\hline Model fit indices (Poor Fitting Models) & & & \\
\hline Parenting practices encouraging PA & & Parenting practices discouraging PA & \\
\hline Satorra-Bentler scaled $x^{2}(\mathrm{df}=85)$ & $393.2 ; p<.001$ & Satorra-Bentler scaled $x^{2}(\mathrm{df}=74)$ & $199.7 ; p<.001$ \\
CFI & 0.86 & CFI & 0.88 \\
RMSEA $(95 \% \mathrm{Cl})$ & $0.07(0.06,0.07)$ & RMSEA $(95 \% \mathrm{Cl})$ & $0.06(0.03,0.08)$ \\
SRMR & 0.08 & SRMR & 0.07 \\
\hline
\end{tabular}

parenting practice sub-scale/item was entered in a second step. The resulting increase in percent variance explained $\left(\mathrm{R}^{2}\right)$ of PA after adding a parenting practice subscale/item was square-rooted to obtain a measure of confounder-adjusted measure of association between a specific PA measure and the parenting practice subscale/ item. As daily minutes of vigorous PA was non-normally distributed (positively skewed), they were log-transformed for the purpose of these analyses. Significance was set at $p<.10$ given the exploratory nature of these last analyses in a relatively small sub-sample [57].

\section{Results}

\section{Confirmatory factor analyses}

The a priori factor structure of the PPAPP subscales for Encouragement and Discouragement of PA demonstrated poor fit to the data, with none of the model-fit indices meeting the pre-established criteria (Table 2). The models were re-specified to improve the fit to the data but retain their conceptual structure (Figure 3). The measurement model for the PPAPP - Encouragement scale was modified by first excluding items with low communalities (defined as standardized loadings $<|.30|$ ) [58] that were not significantly correlated with children's objectively-measured PA (3 items). An additional item (let your child go outside to play around your home) was moved to the PPAPP - Discouragement scale as it had low communality and was conceptually and empirically related to several items gauging Restriction for Safety Concerns, a latent factor underlying responses on the PPAPP - Discouragement scale (see Tables 3 \& 4; Figures 3 \& 4). Although, two single items [not register child for sport/dance due to lack of money (reverse coded, such that higher score approaches "never"); and have outdoor toys available for child] had low communalities (Table 3), they were retained because they significantly correlated with children's PA in the subsample (Table 5). Given that the PPAPP-Encouragement latent factors Parental Responsiveness and Structure were highly correlated $(r=0.95)$, they were combined into a single Parental Engagement factor. The final measurement model for PPAPP - Encouragement (Table 3; Figure 3), consisting of one latent factor (parental engagement: 15 items) with two single items, demonstrated acceptable fit to the data with two indices meeting $\mathrm{Hu}$ and Bentler's [51] stricter criteria of model fit (Table 3).

The measurement model of the PPAPP - Discouragement scale was re-specified by deleting three items with low communalities, defined as $<|.30|$, (all of which belonged to the Promote Inactivity sub-scale), and splitting the Promote Inactivity latent factors into two latent factors: Promote Inactivity and Promote Screen Time

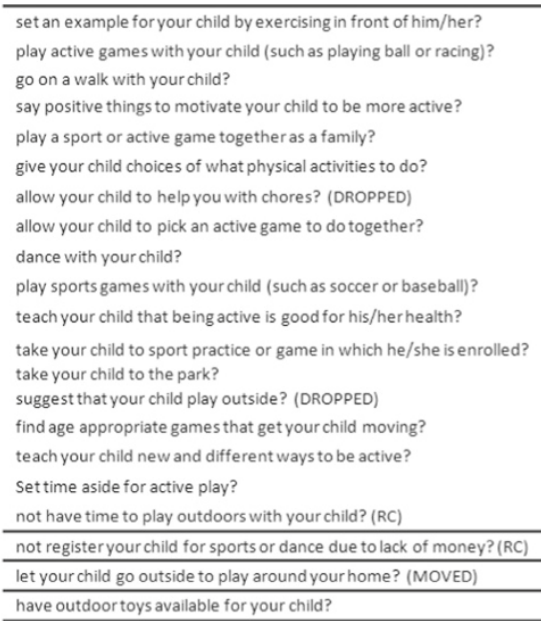

Figure 3 Final model for parenting practices that encourage Latino preschooler's physical activity. 
Table 3 Final measurement model of parenting practices that encourage Latino preschool children to be physically active and item characteristics (mean; standard deviation; skewness; corrected item-scale correlation: standardized loading)

\begin{tabular}{|c|c|c|c|c|}
\hline \multirow{2}{*}{$\begin{array}{l}\text { Items } \\
\text { How often do you... }\end{array}$} & \multicolumn{4}{|c|}{ Parental engagement } \\
\hline & $M(S D)$ & Skewness & CISC & Standardized loading \\
\hline Set an example for your child by exercising in front of him/her? & $3.11(1.14)$ & 0.09 & 0.66 & 0.67 \\
\hline Play active games with your child (such as playing ball or racing)? & $3.44(0.94)$ & 0.08 & 0.71 & 0.75 \\
\hline Go on a walk with your child? & $3.36(0.93)$ & 0.03 & 0.55 & 0.59 \\
\hline Say positive things to motivate your child to be more active? & $4.25(0.82)$ & -0.82 & 0.56 & 0.56 \\
\hline Play a sport or active game together as a family? & $3.25(0.93)$ & 0.05 & 0.69 & 0.75 \\
\hline Give your child choices of what physical activities to do? & $3.53(0.87)$ & 0.03 & 0.62 & 0.69 \\
\hline Allow your child to pick an active game to do together? & $3.39(0.88)$ & 0.20 & 0.63 & 0.68 \\
\hline Dance with your child? & $3.54(0.90)$ & 0.03 & 0.47 & 0.49 \\
\hline Play sports games with your child (such as soccer or baseball)? & $2.91(1.00)$ & 0.11 & 0.58 & 0.61 \\
\hline Teach your child that being active is good for his/her health? & $3.28(1.10)$ & -0.49 & 0.61 & 0.64 \\
\hline Take your child to the park? & $3.41(0.82)$ & 0.26 & 0.45 & 0.52 \\
\hline Teach your child new and different ways to be active? & $3.47(0.92)$ & 0.16 & 0.77 & 0.84 \\
\hline Take your child to sport practice or game in which he/she is enrolled? & $2.28(1.45)$ & 0.66 & 0.37 & 0.31 \\
\hline Find age appropriate games that get your child moving? & $3.49(0.89)$ & -0.17 & 0.49 & 0.53 \\
\hline Set time aside for active play? & $3.10(1.05)$ & -0.01 & 0.65 & 0.67 \\
\hline \multicolumn{5}{|l|}{ Retained single items } \\
\hline Not register your child for sports or dance due to lack of money? (RC) & $3.03(1.43)$ & NA & -0.02 & 0.00 \\
\hline Have outdoor toys available for your child? & $3.88(1.22)$ & NA & -0.84 & 0.00 \\
\hline \multicolumn{5}{|l|}{ Dropped items } \\
\hline Allow your child to help you with chores? & $3.65(0.95)$ & NA & -0.31 & \\
\hline Suggest that your child play outside? & $3.22(1.07)$ & NA & -0.03 & \\
\hline Not have time to play outdoors with your child? & $2.97(0.96)$ & NA & 0.38 & \\
\hline Let your child go outside to play around your home? (moved to discourage) & $3.30(1.10)$ & NA & -0.51 & \\
\hline \multicolumn{5}{|l|}{ Model fit indices (Moderately-fitting model) } \\
\hline Satorra-Bentler scaled $x^{2}(d f=116)$ & 240.94 & \multicolumn{3}{|c|}{$p<.001$} \\
\hline $\mathrm{CFI}$ & 0.90 & & & \\
\hline RMSEA (95\% Cl) & 0.06 & \multicolumn{3}{|c|}{$(0.05,0.07)$} \\
\hline SRMR & 0.08 & & & \\
\hline
\end{tabular}

Legend: $\mathrm{RC}=$ reverse coded; $\mathrm{NA}=$ not applicable; $\mathrm{M}=$ mean; $\mathrm{SD}=$ standard deviation; $\mathrm{CISC}=$ corrected item-scale correlations.

(Table 4; Figure 4). This resulted in four latent factors: Promote Screen Time (3 items), Promote Inactivity (3 items), Psychological Control (5 items), and Restriction for Safety Concerns (4 items). Promote Inactivity was positively related to Promote Screen Time $(\mathrm{r}=.27)$ and Psychological Control $(r=.66)$. The final model fit the data well, with all indices meeting $\mathrm{Hu}$ and Bentler's criteria [51] (Table 4).

\section{Scale reliabilities}

The ICCs of the subscales from the test-retest sample $(n=48)$ indicated moderate to excellent test-retest reliabilities ranging from 0.56 for Restriction for Safety Concerns to 0.85 for Parental Engagement and Psychological Control (Table 6). The internal reliability of the Parental
Encouragement subscale for the total sample was excellent (Cronbach's $\alpha=0.90$; average inter-item correlation 0.38), but less consistent for the PPAPP- Discouragement subscales with fewer items. The average inter-item correlation, a more appropriate assessment of internal reliability in scales with less than 5 items [59] was acceptable for all four Discourage subscales (>.15) [56]. Some of the Discouraging PA sub-scales also had lower Cronbach's $\alpha$ if the questionnaire was completed in Spanish (Table 6). However, post-hoc analyses showed that educational attainment may be confounding this finding, with participants who completed the questionnaire in Spanish less likely to have completed secondary education than their counterparts $(p<0.001$, data not shown). 
Table 4 Final measurement model of parenting practices that discourage Latino preschool children to be physically active and item characteristics (mean; standard deviation; skewness; corrected item-scale correlation; standardized loading)

\begin{tabular}{|c|c|c|c|c|c|c|c|c|c|c|c|c|c|c|c|c|}
\hline \multirow{2}{*}{$\begin{array}{l}\text { Items } \\
\text { How often do you... }\end{array}$} & \multicolumn{4}{|c|}{ Promote screen time } & \multicolumn{4}{|c|}{ Promote inactivity } & \multicolumn{4}{|c|}{ Psychological control } & \multicolumn{4}{|c|}{ Restriction for safety concern } \\
\hline & $M(S D)$ & Sk & CISC & $\overline{\mathrm{SL}}$ & M (SD) & Sk & CISC & $\overline{\mathrm{SL}}$ & $M(S D)$ & Sk & CISC & $\overline{\mathrm{SL}}$ & $M(S D)$ & Sk & CISC & $\overline{S L}$ \\
\hline Allow your child to watch TV for long periods of time? & $2.64(0.91)$ & 0.34 & 0.53 & 0.94 & & & & & & & & & & & & \\
\hline Allow your child to play a lot of videogames? & $1.92(0.90)$ & 0.73 & 0.32 & 0.31 & & & & & & & & & & & & \\
\hline Keep your child occupied by letting him/her watch TV? & $2.63(0.85)$ & 0.13 & 0.45 & 0.55 & & & & & & & & & & & & \\
\hline Carry your child because he/she does not want to walk? & & & & & $2.02(0.96)$ & 0.74 & 0.35 & 0.94 & & & & & & & & \\
\hline Drive your child, when it was easy to walk? & & & & & $2.66(1.19)$ & 0.32 & 0.28 & 0.45 & & & & & & & & \\
\hline Push your child in a stroller instead of letting him/her walk? & & & & & $1.45(0.85)$ & 2.13 & 0.33 & 0.46 & & & & & & & & \\
\hline Not let your child play actively for fear of him/her getting dirty? & & & & & & & & & $1.81(1.01)$ & 1.23 & 0.29 & 0.41 & & & & \\
\hline Tell your child he/she is not good enough at sports or active games? & & & & & & & & & $1.33(1.00)$ & 2.93 & 0.22 & 0.31 & & & & \\
\hline Tell your child he/she will get hurt if he/she plays actively? & & & & & & & & & $2.40(1.13)$ & 0.54 & 0.46 & 0.56 & & & & \\
\hline Discipline your child for being too active? & & & & & & & & & $1.90(1.02)$ & 0.81 & 0.34 & 0.51 & & & & \\
\hline Reward your child for being still? & & & & & & & & & $2.42(1.15)$ & 0.42 & 0.40 & 0.61 & & & & \\
\hline Not let your child play outside because you are worried about traffic? & & & & & & & & & & & & & $2.72(1.20)$ & 0.31 & 0.56 & 0.58 \\
\hline Not let your child play outside because you are worried about crime? & & & & & & & & & & & & & $2.53(1.13)$ & 0.46 & 0.73 & 0.93 \\
\hline Not let your child play outside because you are worried about strangers? & & & & & & & & & & & & & $2.65(1.09)$ & 0.41 & 0.74 & 0.92 \\
\hline Let your child go outside to play around your home? & & & & & & & & & & & & & $3.30(1.10)$ & 0.51 & 0.49 & -0.48 \\
\hline \multicolumn{17}{|l|}{ Dropped items } \\
\hline Not let your child play outside & $2.63(1.07)$ & 0.36 & & & & & & & & & & & & & & \\
\hline $\begin{array}{l}\text { Keep your child occupied with quiet activities } \\
\text { (such as board games and reading)? }\end{array}$ & $3,16(0.93)$ & 0.15 & & & & & & & & & & & & & & \\
\hline Keep your child inside your home all day? & $2.58(0.97)$ & 0.17 & & & & & & & & & & & & & & \\
\hline \multicolumn{17}{|l|}{ Model fit indices (Well fitting model) } \\
\hline Satorra-Bentler scaled $x^{2}(\mathrm{df}=88)$ & & & & & & 114.67 & & & $p<.05$ & & & & & & & \\
\hline CFI & & & & & & 0.96 & & & & & & & & & & \\
\hline RMSEA (95\% CI) & & & & & & 0.04 & & & $(.01, .05)$ & & & & & & & \\
\hline SRMR & & & & & & 0.06 & & & & & & & & & & \\
\hline
\end{tabular}

Legend: $\mathrm{M}=$ mean; $\mathrm{SD}$ = standard deviation; $\mathrm{Sk}=$ skewness; $\mathrm{CISC}=$ corrected item-scale correlations; $\mathrm{SL}$ = standardized loading. 


\begin{tabular}{cl}
\hline 17 & keep your child occupied with quiet activities (such as board games and reading)? \\
10 & (DROPPED) \\
23 & allow your child to watch TV for long periods of time? \\
38 & keepyour child occupied by letting him/her watch TV? \\
\hline 13 & carry your child because he/she does not want to walk? \\
20 & drive your child, when it was easy to walk? \\
8 & not let your child play outside? (DROPPED) \\
29 & keepyour child inside your home all day? (DROPPED) \\
31 & push your child in a stroller instead of letting him/her walk? \\
\hline 4 & not let your child play actively for fear of him/her getting dirty? \\
6 & tell your child he/she is not good enough at sports or active games? \\
25 & tell your child he/she will get hurt if he/she plays actively? \\
27 & discipline your child for being too active? \\
34 & reward your child for being still? \\
\hline 30 & not let your child play outside because you are worried about traffic? \\
36 & not let your child play outside because you are worried about crime? \\
37 & not let your child play outside because you are worried about strangers? \\
32 & let your child go outside to play around your home? (Moved from Encouraging \\
\hline
\end{tabular}

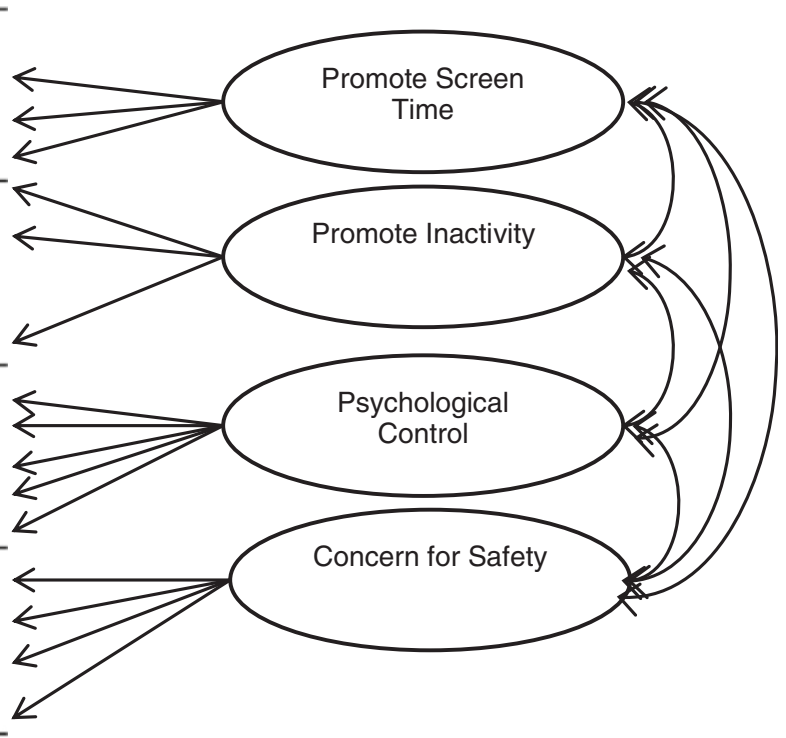

Figure 4 Final model for parenting practices that discourage Latino preschooler's physical activity.

Correlation of PA parenting practice subscales with child PA Several of the parenting practice subscale scores had significant $(p<.10)$ correlations with children's objectively measured PA (Table 5). Promote inactivity was negatively associated with children's LPA and positively with sedentary time; and promote screen time negatively correlated with children's LPA, MPA, and CPM; and positively correlated with children's sedentary time (Table 5). While parental engagement was not correlated with children's PA, the single items "Not register your child for sports or dance due to lack of money", (reverse coded) was positively correlated with children's LPA and MPA, and negatively correlated with children's sedentary time; and "Have outdoors toys available for child", was positively correlated with VPA and CPM. Psychological control was negatively related to sedentary time and positively related to MPA.

\section{Discussion}

Given the prevalence of obesity among Latino children [1], and the protective effects of PA on obesity [4] and other health outcomes $[60,61]$, understanding how parents influence their children's PA is critical to promote healthy lifestyles among families. Valid and reliable measures of PA parenting practices are needed to fully investigate such influences and assess the effects of family based PA interventions. This study demonstrated moderate-togood factorial validity, moderate-to-excellent test-retest reliabilities, and acceptable internal consistency reliabilities of a new parent-report instrument with two independent scales for parenting practices that influence preschooler's PA: the Encouraging and Discouraging PPAPP. One of the scales included parenting practices that encourage Latino preschool-aged children to be physically active. The other scale included parenting practices that discourage them

Table 5 Associations of parenting practices subscale scores with physical activity variables (partial correlation coefficients)

\begin{tabular}{|c|c|c|c|c|c|c|}
\hline Scale/item & Sedentary & Light PA & Moderate PA & Vigorous $\mathrm{PA}^{\#}$ & MVPA & Average CPM \\
\hline Parental engagement (LA-PAPP- Encouragement) & 0.03 & -0.06 & 0.03 & 0.03 & 0.03 & 0.00 \\
\hline $\begin{array}{l}\text { Not register your child for sports or dance due to lack of money } \\
\text { (LA-PAPP- Encouragement; reverse scored) }\end{array}$ & $-0.15 a$ & $0.21^{*}$ & $0.18^{*}$ & 0.08 & 0.09 & 0.11 \\
\hline Have outdoor toys available for child (LA-PAPP- Encouragement) & -0.09 & 0.05 & 0.13 & $0.16 a$ & 0.13 & $0.15 a$ \\
\hline Safety concerns (LA-PAPP- Discouragement) & 0.03 & -0.04 & 0.00 & -0.05 & -0.03 & -0.06 \\
\hline Promote inactivity (LA-PAPP- Discouragement) & $0.15 a$ & $-0.18 a$ & -0.14 & -0.08 & -0.09 & -0.12 \\
\hline Promote screen time (LA-PAPP- Discouragement) & $0.23^{* *}$ & $-0.28^{* *}$ & $-0.23^{*}$ & -0.15 & $-0.20 a$ & $-0.20 a$ \\
\hline Psychological control (LA-PAPP- Discouragement) & $-0.15 a$ & 0.15 & $0.21^{*}$ & 0.05 & 0.13 & 0.13 \\
\hline
\end{tabular}

Legend: PA = physical activity; MVPA = moderate-to-vigorous physical activity; $C P M=$ counts per minute \# = positively skewed variable log-transformed before estimating the associations.

All associations adjusted for wear-time, child's gender and child's age.

a $\mathrm{p}<.10 ;{ }^{*} \mathrm{p}<.05 ;{ }^{* *} \mathrm{p}<.01$. 
Table 6 Subscale test-retest and internal reliabilities

\begin{tabular}{|c|c|c|c|c|c|c|c|}
\hline \multirow{3}{*}{ Subscales } & \multicolumn{3}{|c|}{ Test-retest reliability $(n=48)$} & \multicolumn{4}{|c|}{ Internal reliability $(n=240)$} \\
\hline & \multirow[t]{2}{*}{ ICC (95\% Cl) } & \multicolumn{2}{|c|}{ Mean (SD) } & \multirow{2}{*}{$\begin{array}{l}\text { Average inter-item } \\
\text { correlation }\end{array}$} & \multicolumn{3}{|c|}{ Cronbach's alpha } \\
\hline & & Assessment 1 & Assessment 2 & & Total & English & Spanish \\
\hline \multicolumn{8}{|l|}{ Practices that encourage child PA } \\
\hline Engagement (15 items) & $0.85(0.75,0.91)$ & $3.51(0.62)$ & $3.47(0.58)$ & 0.38 & 0.90 & 0.87 & 0.92 \\
\hline $\begin{array}{l}\text { How often do you not register your } \\
\text { child for sports or dance due to lack } \\
\text { of money? (single item) }\end{array}$ & $0.62(0.41,0.76)$ & $2.81(1.42)$ & $2.52(1.22)$ & & & & \\
\hline $\begin{array}{l}\text { How often do you have outdoor toys } \\
\text { available for your child? (single item) }\end{array}$ & $0.57(0.34,0.74)$ & $3.69(1.37)$ & $3.77(1.24)$ & & & & \\
\hline \multicolumn{8}{|l|}{ Practices that discourage child PA } \\
\hline Promote inactivity (3 items) & $0.59(0.38,0.85)$ & $2.09(0.80)$ & $1.92(0.70)$ & 0.26 & 0.50 & 0.53 & 0.43 \\
\hline Promote screen time (3 items) & $0.62(0.41,0.77)$ & $2.30(0.65)$ & $2.23(0.56)$ & 0.34 & 0.61 & 0.65 & 0.57 \\
\hline Psychological control (5 items) & $0.85(0.75,0.91)$ & $2.11(0.70)$ & $2.03(0.69)$ & 0.26 & 0.59 & 0.67 & 0.49 \\
\hline Restriction for safety concerns (4 items) & $0.56(0.33,0.73)$ & $2.62(0.88)$ & $2.55(0.95)$ & 0.53 & 0.82 & 0.81 & 0.80 \\
\hline
\end{tabular}

Legend: ICC = Intra-class correlation.

Assessment 1 and 2 were about 2 weeks apart.

from being physically active comprised of four factors: promote screen time, promote inactivity, psychological control, and restriction for safety concerns.

Although the existing literature on PA parenting practices has focused on practices intended to positively impact mostly older children's PA [21,62], this study demonstrated that among Latino preschool children, parenting practices can also discourage PA, as indicated by correlations of both the Promote Inactivity $(\mathrm{p}<.10)$ and the Promote Screen Time $(\mathrm{p}<.01)$ subscales with children's objectively measured PA. Gubbels et al. have previously demonstrated that, among a Dutch sample of 5 year olds, parental restriction of sedentary time (measured by a 6-item non-validated subscale) was associated with parent reports of lower child PA [17]. However, to our knowledge this is the first PA parenting scale that has included a subscale to assess whether parents promoted inactive transport among children, such as pushing them in a stroller or carrying them when they could have walked. Active transportation has been associated with adolescents', but not children's, PA [63]. The initial exploratory analyses presented here suggest that parenting to promote inactive transport may be associated with less LPA among Latino preschoolers and warrants further investigation.

Also new in this PA parenting scale is the construct of psychological control by parents which may undermine or inhibit children's PA. The construct of psychological control has been dominant in the developmental psychology parenting literature for decades [25] and suggested for PA parenting [32], but has not been assessed in the PA parenting literature. For this instrument, psychological control was created based on qualitative research with Latino parents who reported they believed that parents who criticize or insult their child, discipline their child for being active, or restrict their child's activities for fear of them getting hurt tend to discourage their child from engaging in PA [24]. It was found to be positively associated with Latino preschooler's moderate PA and negatively associated with their sedentary time. In this cross-sectional study we cannot delineate whether psychological control causes young children to be more active, or whether parents whose children are more active are more likely to use psychological control.

The fourth sub-scale for Discouraging PPAPP was restriction for safety concerns. A systematic review demonstrated that neighborhood safety was associated with children's PA [42]; and it is likely that this relationship is in part mediated by parents' concerns about the safety of the environment in which they allow their child to play. The new subscale of Restriction for Safety Concerns will allow further exploration of this hypothesis. Future research in larger and/or longitudinal samples will need to identify whether these constructs are important social determinants of children's PA.

The discouraging subscales had slightly lower mean scores compared to the encouraging scale or single items (Table 6), which may suggest that parents are less likely to use parenting practices that discourage PA, but when used they have an important negative impact on children's PA. Alternatively, parents may be less likely to self-report using parenting practices that discourage their child from being active.

Parenting practices that encourage child PA included one subscale for parental engagement for child PA that represented parenting practices that are responsive and provide structure to support PA [32]. Previous work in 
developmental psychology has demonstrated that parental involvement or engagement in children's schooling mediated the positive effects of authoritative parenting on children's school success [26]. Similarly, parental engagement or involvement with young children's PA may positively influence children to be physically active. The addition of two single items to the encouraging PA parenting practice scale suggests that these two items represent additional latent constructs that warrant further development with additional items. These two items [not register child for sport/dance due to lack of money (reverse coded); and have outdoor toys available for child] may be markers of parenting practices as well as living conditions, such as family income and/or type of residence. As such they may not represent actual parenting practices, but rather socioeconomic factors that influence parenting behaviors.

This study has many strengths: the systemic development of the PA parenting practice scales were based on a proposed theoretical framework for PA parenting [32], qualitative studies with Latino parents of preschoolers [24]; extensive psychometric analyses of the new PPAPP scales were conducted; and the criterion validity was based on objectively-measured child PA. However, there are also limitations. The PPAPP is a self-report instrument and is therefore prone to reporting biases, including socially desirable responses. However, self-report instruments are needed to investigate the influence of parents on children's PA in larger samples, since direct observations are costly and often impractical. Additional studies to assess the convergent validity of this instrument with parent behaviors using direct observations would help strengthen its validity. The parents completed the PPAPP in English or Spanish, but the sample size was not large enough to look at the factorial invariance separately for the two languages. Instead, Cronbach's alphas were assessed separately for those who completed the questionnaire in English or Spanish. Some variations in Cronbach's alphas were found with lower scores among some of the Spanish language sub-scales for Discouraging PA. It is possible this is due to differences in the robustness of those subscales by language. However, educational attainment was significantly lower among those who completed the questionnaire in Spanish than those who completed it in English. Participants with low educational attainment may have found it more difficult to respond to some of the items. Among older samples of children, mothers and fathers have different influences on their children's PA $[14,20]$, suggesting their influence should be assessed separately. However, the scales should be developed for use with both mothers and fathers, which is why the samples were combined in this developmental study. Only a subsample of children wore the accelerometers which limited our ability to detect correlations of parenting practices subscales with children's PA.

Future research should assess the predictive validity of the PPAPP on Latino preschool children's PA in larger samples and the potential different influence by mothers and fathers on their same and different gendered children $[14,20]$. In addition, the PPAPP instrument should be refined by expanding the single items in the Encourage PA scale to multiple-item subscale. The psychometrics and predictive validity of this scale should also be cross-validated in another Latino sample and assessed in other populations, such as Non-Hispanic white, African American, and Asian, to assess its usefulness for assessing PA parenting practices regardless of race or ethnicity.

\section{Conclusion}

The PPAPP had moderate-to-good factorial validity, moderate-to-excellent test-retest reliabilities, and acceptable internal reliabilities among a sample of Latino parents of preschool children. This new and preliminary instrument should be further evaluated to assess its association with children's PA and offers a new research tool for measuring parenting practices among Latino families.

\section{Abbreviations}

BCM: Baylor College of Medicine; CFA: Comparative fit analysis; CFI: Comparative fit index; CNRC: Children's Nutrition Research Center; CPM: Counts per minute; ICC: Intra-class correlation coefficient; LPA: Light physical activity; MPA: Moderate physical activity; NGT: Nominal group technique; PA: Physical activity; PPAPP: Preschoolers' PA Parenting Practices; RMSEA: Root mean square error of approximation; SRMR: Standardized root mean-square residual; VPA: Vigorous physical activity.

\section{Competing interests}

The authors declare they have no competing interests.

\section{Authors' contributions}

TMO was the PI on the NIH funded R21 study: Ninos Activos, developed the study design for the development of the physical activity parenting practice questionnaire, oversaw all aspects of the study protocols, data collection, and drafted the manuscript. EC developed the Ninos Activos recruitment strategies and plans for analyses, conducted the analyses for this study, and regularly attended study meetings. $\mathrm{SOH}$, a parenting expert in child feeding, assisted with the qualitative formative studies to inform the PA parenting items, provided expertise in expected factor structure of the PA parenting scales, regularly attended study meetings, and helped interpret the data analyses. JR was the study coordinator on the project who recruited and coordinated informed consent, and data collection of all participants. She regularly attended study meetings, and provided critical input on implementing study protocols. DIT is a qualitative researcher who trained the study staff in cognitive interview methodology, and informed the development of the interview questions. JAM provided input on the Ninos Activos study design and interpretation of analysis during bi-weekly study meetings. TB provided input on the Ninos Activos study design and interpretation of analysis during bi-weekly study meetings. REL provided input on the Ninos Activos study design and interpretation of analysis during biweekly study meetings. All authors critically read, edited, and approved the manuscript.

\section{Acknowledgements}

This study was funded by NIH-Eunice Kennedy Shriver National Institute of Child Health \& Human Development (R21HD060925). This work is a publication of the US Department of Agriculture (USDA/ARS) Children's Nutrition 
Research Center, Department of Pediatrics, BCM through a cooperative agreement (USDA/ARS 6250-51000-053-20S). JAM was supported, in part, by a career development award (K07CA131178). The contents of this publication do not necessarily reflect the views or policies of the USDA or $\mathrm{NIH}$, nor does mention of organizations imply endorsement from the US government. The Spanish version is available upon request.

\section{Author details}

'USDA/ARS Children's Nutrition Research Center, Department of Pediatrics, Baylor College of Medicine, 1100 Bates St, Houston, TX 77030, USA. ${ }^{2}$ Academic General Pediatrics, Department of Pediatrics, Baylor College of Medicine, Houston, TX, USA. ${ }^{3}$ Institute of Human Performance, The University of Hong Kong, Pokfulam Road, Pokfulam, Hong Kong SAR. ${ }^{4}$ Centre for Physical Activity and Nutrition, School of Exercise and Nutrition Sciences, Deakin University, Burwood, Australia. ${ }^{5}$ College of Nursing and Health Innovation, Arizona State University, Phoenix, USA. ${ }^{6}$ Division of General Pediatrics, Department of Pediatrics, University of Washington School of Medicine, Seattle, WA, USA.

Received: 23 April 2013 Accepted: 10 January 2014

Published: 15 January 2014

\section{References}

1. Ogden C, Carroll M, Kit B, Flegal K: Prevalence of obesity and trends in body mass index among US children and adolescents, 1999-2010. JAMA 2012, 307:483-490.

2. Goran MI, Ball GD, Cruz ML: Obesity and risk of type 2 diabetes and cardiovascular disease in children and adolescents. $J$ Clin Endocrino Metab 2003, 88:1417-1427.

3. Moore LL, Nguyen US, Rothman KJ, Cupples LA, Ellison RC: Preschool physical activity level and change in body fatness in young children. The Framingham Children's Study. Am J Epidemiol 1995, 142:982-988,

4. Jago R, Baranowski T, Baranowski JC, Thompson D, Greaves KA: BMI from 3-6 $\mathrm{y}$ of age is predicted by TV viewing and physical activity, not diet. Int J Obes (Lond) 2005, 29:557-564.

5. Trost SG, Sirard JR, Dowda M, Pfeiffer KA, Pate RR: Physical activity in overweight and nonoverweight preschool children. Int I Obes Relat Metab Disord 2003, 27:834-839.

6. Pate RR, Baranowski T, Dowda M, Trost SG: Tracking of physical activity in young children. Med Sci Sports Exerc 1996, 28:92-96.

7. O'Connor TM, Jago R, Baranowski T: Engaging parents to increase youth physical activity: a systematic review. Am J Prev Med 2009, 37:141-149.

8. Caspersen CJ, Powell KE, Christenson GM: Physical activity, exercise, and physical fitness: definitions and distinctions for health-related research. Public Health Rep 1985, 100:126-131.

9. National Association of Sports and Physical Education: Active start: $A$ statement of physical activity guidelines for children from birth to age 5 . http://www.aahperd.org/naspe/standards/nationalGuidelines/ActiveStart.cfm.

10. Stokols D: Translating social ecological theory into guidelines for community health promotion. Am J Health Promot 1996, 10:282-298

11. Bandura A: Health promotion by social cognitive means. Health Educ Behav 2004, 31:143-164.

12. Welk GJ, Wood K, Morss G: Parental influences on physical activity in children: an exploration of potential mechanisms. Ped Exerc Sci 2003, 15:19-33.

13. Darling N, Steinberg L: Parenting style as context: an integrative model. Psychol Bull 1993, 113:487-496.

14. Davison KK, Cutting TM, Birch LL: Parent's activity-related parenting practices predict girls' physical activity. Med Sci Sports Exerc 2003,35:1589-1595.

15. Jago R, Davison KK, Brockman R, Page AS, Thompson JL, Fox KR: Parenting style, parenting practices, and physical activity in 10-11 year olds. Prev Med 2011, 52:44-47.

16. Sleddens EF, Kremers SP, Hughes SO, Cross MB, Thijs C, De Vries NK, O'Connor TM: Physical activity parenting: a systematic review of questionnaires and their association with child activity levels. Obes Rev 2012, 13:1015-1033.

17. Gubbels JS, Kremers SP, Stafleu A, de Vries SI, Goldbohm RA, Dagnelie PC, de Vries NK, van Buuren S, Thijs C: Association between parenting practices and children's dietary intake, activity behavior, and development of body mass index: the KOALA Birth Cohort Study. Int J Behav Nutr Phys Act 2011, 8:18.
18. Sallis JF, Taylor WC, Dowda M, Freedson PS, Pate RR: Correlates of vigorous physical activity for children in grades 1 through 12: comparing parentreported and objectively measured physical activity. Pediatr Exerc Sci 2002, 14:30-44.

19. Oliver M, Schofield GM, Schluter PJ: Parent influences on preschoolers' objectively assessed physical activity. J Sci Med Sport 2010, 13:403-409.

20. Beets MW, Cardinal BJ, Alderman BL: Parental social support and the physical activity- related behaviors of youth: a review. Health Educ Behav 2010, 37:621-644

21. Edwardson CL, Gorely T: Activity-related parenting practices and children's objectively measured physical activity. Pediatr Exerc Sci 2010, 22:105-113.

22. Varela RE, Vernberg EM, Sanchez-Sosa JJ, Riveros A, Mitchell M, Mashunkashey J: Parenting style of Mexican, Mexican American, and Caucasian-nonHispanic families: social context and cultural influences. J Fam Psychol 2004, 18:651-657.

23. Taverno SE, Rollins BY, Francis LA: Generation, language, body mass index, and activity patterns in Hispanic children. Am J Prev Med 2010, 38:145-153.

24. O'Connor TM, Cerin E, Hughes SO, Robles J, Thompson D, Baranowski T, Lee RE, Nicklas T, Shewchuk RM: What Hispanic parents do to encourage and discourage 3-5 year old children to be active: a qualitative study using nominal group technique. Int J Behav Nutr Phys Act 2013, 10:93.

25. Grolnick WS, Pomerantz EM: Issues and challenges in studying parental control: toward a new conceptualization. Child Dev Perspect 2009, 3:165-170.

26. Steinberg L, Lamborn SD, Dornbusch SM, Darling N: Impact of parenting practices on adolescent achievement: authoritative parenting, school involvement, and encouragement to succeed. Child Dev 1992, 63:1266-1281

27. Hughes SO, O'Connor TM, Power TG: Parenting and children's eating patterns: examining control in a broader context. Int $J$ Child Adolesc Health 2008, 1:323-330.

28. Weir LA, Etelson D, Brand DA: Parents' perceptions of neighborhood safety and children's physical activity. Prev Med 2006, 43:212-217.

29. de la Haye K, de Heer HD, Wilkinson AV, Koehly LM: Predictors of parentchild relationships that support physical activity in Mexican-American families. J Behav Med 2012. Epub ahead of print.

30. O'Dwyer MV, Fairclough SJ, Knowles Z, Stratton G: Effect of a family focused active play intervention on sedentary time and physical activity in preschool children. Int J Behav Nutr Phys Act 2012, 9:117.

31. Larios SE, Ayala GX, Arredondo EM, Baquero B, Elder JP: Development and validation of a scale to measure Latino parenting strategies related to children's obesigenic behaviors. The parenting strategies for eating and activity scale (PEAS). Appetite 2009, 52:166-172.

32. Davison KK, Masse LC, Timperio A, Frenn MD, Saunders J, Mendoza JA, Gobbi E, Hanson P, Trost SG: Physical activity parenting measurement and research: challenges, explanations, and solutions. Child Obes 2013, 9:S103-S109.

33. Delbeca AL, Van de Ven AH, Gustafson DH: Group Techniques for Program Planning: A Guide to Nominal Group and Delphi Processes. Scott Foresman: Glenview, IL; 1975

34. MacPhail A: Nominal Group Technique: a useful method for working with young people. Br Educ Res J 2001, 27:161-170.

35. Power TG: Parenting dimensions and styles: a brief history and recommendations for future research. Child Obes 2013, 9:S14-S21.

36. Edwards JR, Bagozzi RP: On the nature and direction of relationships between constructs and measures. Psychol Methods 2000, 5:155-174.

37. Dwyer J, Needham L, Simpson JR, Hennessey ES: Parents report intrapersonal, interpersonal, and environmental barriers to supporting healthy eating and physical activity among their preschoolers. Appl Physiol Nutr Metab 2008, 33:338-346.

38. O'Connor T, Watson K, Hughes S, Beltran A, Hingle M, Baranowski J, Campbell K, Canal DJ, Lizaur AB, Zacarias I, Gonzalez D, Nicklas T, Baranowki T: Health professionals' and dietetics practitioners' perceived effectiveness of fruit and vegetable parenting practices across six countries. J Am Diet Assoc 2010, 110:1065-1071.

39. Baranowski T, Chen TA, O'Connor T, Hughes S, Beltran A, Frankel L, Diep C, Baranowski JC: Dimensions of vegetable parenting practices among preschoolers. Appetite 2013, 69:89-93. 
40. Willis $\mathrm{GB}(\mathrm{Ed})$ : Cognitive interviewing and questionnaire design: A training manual. Hyattsville, MD: National Center for Health Statistics, Office of Research and Methodology, Cognitive Staff Working Paper Series; 1994.

41. Willis $\mathrm{G}$ : Analyzing and documenting cognitive interview results. In Cognitive Interviewing: A Tool for Improving Questionnaire Design. Edited by Shaw L. Thousand Oaks, CA: SAGE Publications; 2005:151-174.

42. Davison KK, Lawson CT: Do attributes of the physical environment influence children's physical activity? A review of the literature. Int J Behav Nutr Phys Act 2006, 3:19.

43. US Department of Commerce: United States Census Bureau. 2012. http://www.census.gov.

44. Dickin KL, Lent M, Lu AH, Sequeira J, Dollahite JS: Developing a measure of behavior change in a program to help low-income parents prevent unhealthful weight gain in children. J Nutr Educ Behav 2012, 44:12-21.

45. Chaidez V, Kaiser LL: Validation of an instrument to assess toddler feeding practices of Latino mothers. Appetite 2011, 57:229-236.

46. Hughes SO, Power TG, Orlet Fisher J, Mueller S, Nicklas TA: Revisiting a neglected construct: parenting styles in a child-feeding context. Appetite 2005, 44:83-92.

47. Cliff DP, Reilly JJ, Okely AD: Methodological considerations in using accelerometers to assess habitual physical activity in children aged 0-5 years. J Sci Med Sport 2009, 12:557-567.

48. Pate RR, Almeida MJ, Mclver KL, Pfeiffer KA, Dowda M: Validation and calibration of an accelerometer in preschool children. Obesity 2006, 14:2000-2006

49. van Cauwenberghe E, Labarque V, Trost SG, de Bourdeaudhuij I, Cardon G: Calibration and comparison of accelerometer cut points in preschool children. Int J Pediatr Obes 2010, 6:e582-e589.

50. Jöreskog KG, Sörbom D: LISREL 8: Structural Equation Modeling with the SIMPLIS Command Language. Chicago, IL: Scientific Software International; 1993.

51. Hu L, Bentler PM: Evaluating model fit. In Structural Equation Modeling: Concepts, Issues, and Applications. Edited by Hoyle RH. Thousand Oaks, CA: Sage Publications; 1995:76-99.

52. Kline RB: Principles and Practice of Structural Equation Modeling. 2nd edition New York, NY: Guilford Press; 2005.

53. Satorra A, Bentler PM: A scaled difference chi-square test statistic for moment structure analysis. Psychometrika 2001, 66:507-514.

54. Shrout PE, Fleiss JL: Intraclass correlations: uses in assessing rater reliability. Psychol Bull 1979, 86:420-428.

55. Landis JR, Koch GG: The measurement of observer agreement for categorical data. Biometrics 1977, 33:159-174.

56. Clark LA, Watson D: Construct validity: basic issues in objective scale development. Psychol Assess 1995, 7:309-319.

57. Baghi H, Noorbaloochi S, Moore JB: Statistical and nonstatistical significance: implications for health care researchers. Qual Manag Health Care 2007, 16:104-112.

58. Bryant FB, Yarnold PR: Principal-components analysis and exploratory and confirmatory factor analysis. In Reading and Understanding Multivariate Statistics. Edited by Grimm LG, Yarnold PR. Washington, DC: APA; 1995:99-136.

59. Voss KE, Stem DE Jr, Fotopoulos S: A comment on the relationship between coefficient alpha and scale characteristics. Mark Lett 2000, 11:177-191.

60. Boreham C, Twisk J, Murray L, Savage M, Strain JJ, Cran G: Fitness, fatness, and coronary heart disease risk in adolescents: the Northern Ireland Young Hearts Project. Med Sci Sports Exerc 2001, 33:270-274.

61. Schmitz KH, Jacobs DR Jr, Hong CP, Steinberger J, Moran A, Sinaiko AR: Association of physical activity with insulin sensitivity in children. Int J Obes Relat Metab Disord 2002, 26:1310-1316.

62. Pugliese J, Tinsley B: Parental socialization of child and adolescent physical activity: a meta-analysis. J Fam Psychol 2007, 21:331-343.

63. Carver A, Timperio AF, Hesketh KD, Ridgers ND, Salmon JL, Crawford DA: How is active transport associated with children's and adolescents' physical activity over time? Int J Behav Nutr Phys Act 2011, 8:126.

doi:10.1186/1479-5868-11-3

Cite this article as: O'Connor et al:: Psychometrics of the preschooler physical activity parenting practices instrument among a Latino sample. International Journal of Behavioral Nutrition and Physical Activity 2014 11:3.

\section{Submit your next manuscript to BioMed Central and take full advantage of:}

- Convenient online submission

- Thorough peer review

- No space constraints or color figure charges

- Immediate publication on acceptance

- Inclusion in PubMed, CAS, Scopus and Google Scholar

- Research which is freely available for redistribution 